\title{
Professional Commitment and Career Maturity of Full-Time Nursing Postgraduates in China: A Cross-Sectional Study
}

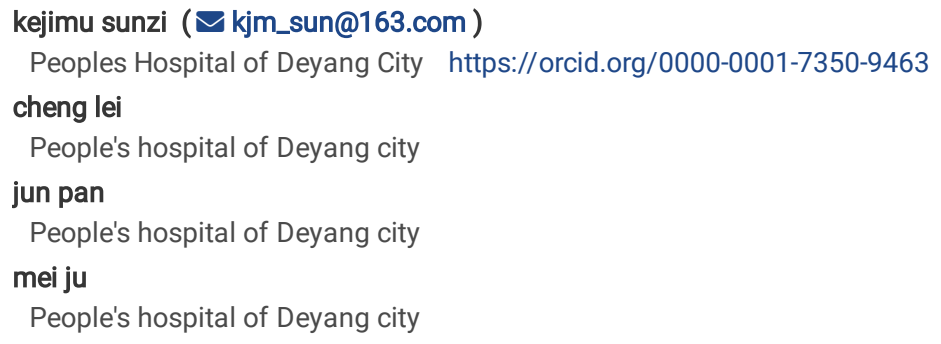




\section{Abstract}

Background: Nursing is becoming ever more demanding, and is regarded as a stressful occupation because of manpower shortages and various other challenges associated with nursing practice.This article describes the students' professional commitment and career maturity, and students establish their career objectives during the early stages of their graduate study.

Methods: A cross sectional\survey design was conducted at universities in China. A sample of 184 students was selected using the professional commitment scale and career maturity scale to investigate the status quo of professional commitment and career maturity of full-time nursing postgraduates. Data was collected using self-designed demographic characteristics of the student, professional commitment scale, career maturity scale in $2019 . D$ ata was analyzed using correlation coefficient test $(a<0.05)$.

Results: Participants returned 184 surveys (response rate, $100 \%)$. Career maturity (105.12 \pm 11.13$)$, Specialty commitment(90.0 \pm 12.09$)$,Career maturity was positively correlated with Professional Commitment $(r=0.20)$.

Conclusions: The career maturity and professional commitments of full-time nursing postgraduates were of an average level. Career planning courses could be useful to strengthen the vocational education of the post-graduate students.

\section{Background}

With the development of medical technology and societal progress, the demand for nursing education has increased. Typically, studies on nursing training at the post-graduate level focus on the educational evaluation index, and core competence of the postgraduates. however, their commitment to professional development and career maturity has rarely been reported. Our research explored the professional commitment and career maturity of post-graduate students in nursing education.

The aging population adds an enormous burden on the health care system and, a shortage of nursing staff has become a worldwide problem. China, as an example, lacks nurses with higher education. Studies have shown that there is a positive correlation between highly educated nurses and low mortality rates of the patients [1]. According to the National Health Commission of the People's Republic of China, there were 3.8 million registered nurses in 2017, of which only $0.7 \%$ of registered nurses have master's or doctoral degrees [2]. As a result, the hospitals' demand for nurses with a specialized degree has increased to accelerate the coverage of health resources, and services. Therefore we intensified our efforts to study the nursing graduate students (masters) in China.

With an increase in demand for nursing education in colleges and universities, the recruitment of students for the post-graduate study has also escalated. Consequently, these students face unprecedented employment pressure and competition in society. At the same time, studies have found that the nursing graduate students have no career orientation and excessively high occupational expectations [3-5]. In China, the undergraduate students are directly transferred for postgraduate studies, therefore, they have limited clinical experience. Career maturity represents both the extent of career development and readiness to engage in occupational selectio, as one of the main areas of career development guidance, is an essential factor for career preparedness in modern society [6]. Under such conditions, they face higher employment pressure. Thus, it is necessary to carry out pre-service orientation for them to accelerate the construction of the nursing discipline and reduce the turnover rate of nursing staff. In this respect, two key aspects are crucial to improve the maturity of nursing post-graduate students. First, most studies have shown that career maturity directly affects the career choices of a nursing post-graduate, and their subsequent career adaptation, satisfaction, and success [7-8]. Typically, the higher is the career maturity, the stronger is the career choice, planning, and execution of the nursing profession. College students with higher career maturity exhibited a greater realization of their potential and a higher degree of social adjustment than those with lower career maturity. Second, the Professional Commitment constitutes an individual's identification, loyalty, and commitment to the performed work. The higher is the professional commitment, the more effort a professional put forward into the nursing profession, which fuels his/her desire to invest more in nursing.

At present, the research on professional commitment and career maturity is aimed at nursing students, and there is no research on the professional maturity of the nursing masters [9]. This study conducted a cross-sectional survey of masters' students in nursing education. We investigated their career maturity and professional commitment levels to suggest personalized career planning strategy that allows nursing graduate students to achieve satisfactory employment.

\section{Career maturity}

Career maturity as a construct of career psychology principally reflects an individual's degree of mental maturity. Accoring to the career maturity model, the construct includes both congnitive and affective dimensions.Career maturity,defined as the individual's ability to make appropriate career choices, comprises an awareness of what is required to make a carrer choice and the extent to which one's carrer decisions are both realistic and consistent over time [10].

\section{Professional Commitment}

Professional commitment in nursing is an ongoing, dynamic process, which is originally shaped during the education of the nursing students in school. Which means if nursing students have a higher professional commitment in school, they will continue to have a higher professional

commitment after they graduate and become a registered nurse in a hospital setting [8].

\section{Methods}

\subsection{Sample and setting}


A convenience sample of full-time nursing master students within the period of January 2019 to April 2019 was derived from Chinese universities. Out of the 200 eligible students, 184 of them participated in the study, representing a response rate of $92 \%$. An online questionnaire survey was conducted to collect the respondents' demographic information, career maturity and, professional commitment scale. The participants were included if they met the following inclusion criteria, i.e., the students (1) were from China who were receiving full-time graduate education, (2) were enrolled full-time in a 3-year, science degree course, (3) voluntarily participated, and (4) correctly understood the context of the questionnaire. 184 students from 11 provinces and cities in China completed this research. The exclusion criteria were: (1) students performing an international university exchange or clinical placements in other provinces at the time of the study, (2) questionnaires that were unintelligible, or in which no independent variable was selected.

\subsection{Instrument}

1. 2.2.1.Demographic Characteristics: A questionnaire was used to obtain the demographic characteristics of the participants, including grade, gender, age etc.

2. 2.2.2. The Professional commitment scale: The level of professional commitment was measured by the Professional Commitment Scale, which is divied into four dimensions: affective commitment ( 9 items), continuance commitment ( 6 items), normative commitment (5 items), and ideal commitment (7 items). Responses were rated on a 5-point Likert sacle, and each iteam was rated on a scale from 1 (nonconformity) to 5 (conformity) with higher scores indicating greater commitment. This scale has been used in previous studies, and the alpha coefficient for the scale was reported in previous research as 0.927 and it also has good construct validity [11]. The present study is concerned with only the achievement scale.

3. 2.2.3.Career maturity scale: The Chinese student career maturity inventory was used to assess the nursing student's level of career maturity. The inventory consisted of 34 items that assessed six dimensions: career decisiveness, carrer confidence, career independence, career value, relational dependence, and career reference. A previous study used this scale to assess students's level of career maturity. Participants were asked to complete the self-reported career maturity inventory based on their perceptions of each item. Responses were rated using a 5-point Likert scale $(1=$ completely disagree to $5=$ completely agree). The total mean score was computed by averaging of the summing of the items. The inventory had a reasonable internal consistency coefficient with Cronbach's alpha $=0.869$. The Cronbach's alpha for this sample was $0.76[8]$.

\subsection{Data collection}

This study was conducted at three nursing-colleges. Online survey was adopted in this study, the purpose of this study was explained at the beginning of the questionnaire, and the independent participation and confidentiality of the answers were emphasized to the research object. The professional commitment and career maturity scales were also measured. During the period from January to March 2019 in our study, the most widely used and popular application WeChat was used to issue the questionnaire online, and the respondents completed the questionnaire independently.

\subsection{Statistical analysis}

All statistical analyses were performed using Statistical Packages for Social Science (SPSS) version 23.0 (IBM Corporation, New York, NY. USA). Percentages and frequencies, were determined for descriptive statistics, variables, and responses,and means and SD were determined for continuous variables. The demographic information data were statistically described by frequency and percentage. The total score of professional commitment and career maturity and the ratings of each dimension were expressed by mean (SD standard) deviation. Pearson correlation analysis was used to analyze the correlation between professional commitment and career maturity. A $P$ value less than 0.05 was considered to be statistically significant.

\subsection{Ethical considerations}

The study followed the Code of Ethics of the Declaration of Helsinki, and the ethical approval for the project was obtained from the ethics committees of the affiliated hospital. Before the study questionnaires were distributed all participants were clearly instructed that this was an independent research study and that they had the full autonomy to participate without any rewards or consequences on their schools. All the participants had the full freedom to choose whether to participate or not. Our study maintained the anonymity of all the participants. We further guaranteed that the identity of the participants remained confidential, and their answers were only used for scientific analysis. The participants were also ensured that they would not be affected after the withdrawal, or completrion of the investigation process.

\section{Results}

\subsection{Participants}

Table 1 presents a detailed demographics of the Chinese nursing graduate students (184) who were participated in the survey using an online questionnaire (response rate was $100 \%)$. There were 19 males (10.30\%) and 165 females (89.70\%). The participants were 22 to 34 years old,with a mean age of 25.82 years old(SD 2.73). Consisted of $10.30 \%$ male $(n=19)$, and $89.70 \%$ female $(n=165)$. All of them were accepting full-time education. Among them, 74 students $(40.22 \%)$ were in the first grade, 47 students $(25.54 \%)$ were in the second grade, and 63 students $(34.24 \%)$ were in the third grade. 
Table 1

Demographic characteristics of students $(n=184, \%)$

\begin{tabular}{|c|c|c|c|}
\hline Variate & group & Frequency(n) & Percentage(\%) \\
\hline \multirow[t]{2}{*}{ Gender } & Male & 19 & $10.30 \%$ \\
\hline & Female & 165 & $89.70 \%$ \\
\hline age & $22 \rrbracket 34$ & & \\
\hline \multirow[t]{2}{*}{ Birthplace } & Countryside & 86 & $46.74 \%$ \\
\hline & City & 98 & $53.26 \%$ \\
\hline \multirow[t]{2}{*}{ Only child } & Yes & 58 & $31.52 \%$ \\
\hline & No & 126 & $68.48 \%$ \\
\hline \multirow[t]{3}{*}{ School type } & 985 & 20 & $10.87 \%$ \\
\hline & 211 & 26 & $14.13 \%$ \\
\hline & university & 148 & $80.43 \%$ \\
\hline \multirow[t]{3}{*}{ Grade } & Freshman & 74 & $40.22 \%$ \\
\hline & Sophomore & 47 & $25.54 \%$ \\
\hline & Junior & 63 & $34.24 \%$ \\
\hline \multirow[t]{4}{*}{ Admission method } & Be recommended for free & 30 & $16.30 \%$ \\
\hline & Completed the undergraduate & 74 & $40.22 \%$ \\
\hline & after clinical work & 66 & $35.87 \%$ \\
\hline & other & 14 & $7.61 \%$ \\
\hline \multirow[t]{2}{*}{ Whether as a student cadre } & Yes & 52 & $28.26 \%$ \\
\hline & No & 132 & $71.74 \%$ \\
\hline \multirow[t]{3}{*}{ Whether positively } & Yes & 100 & $54.35 \%$ \\
\hline & No & 15 & $8.15 \%$ \\
\hline & General & 69 & $37.50 \%$ \\
\hline \multirow[t]{5}{*}{ Father's education level } & Primary and below & 46 & $25.00 \%$ \\
\hline & High school & 105 & $57.07 \%$ \\
\hline & Secondary school & 14 & $7.61 \%$ \\
\hline & college /junior college & 2 & $1.09 \%$ \\
\hline & Master degree or above & 0 & $0.00 \%$ \\
\hline \multirow[t]{5}{*}{ Mother's education level } & Primary and below & 62 & $33.70 \%$ \\
\hline & High school & 100 & $54.35 \%$ \\
\hline & Secondary school & 8 & $4 \llbracket 35 \%$ \\
\hline & college /junior college & 13 & $7.07 \%$ \\
\hline & Master degree or above & 1 & $0.54 \%$ \\
\hline \multirow[t]{2}{*}{ Whether parents work in medicine } & Yes & 14 & $7.61 \%$ \\
\hline & No & 170 & $92.39 \%$ \\
\hline
\end{tabular}

\subsection{Scale scores of professional commitment and career maturity}

The questionnaire scores of the career maturity ranged from 52 to 133 , the total average rating was 105.12 (SD 11.13), and the items scored 3.09 (SD 0.33 ). And the scores of professional commitment ranged from 45 to 124, with an average score of 90.0 (SD 12.09) and the items scored 3.33 (SD 0.447 ). The scores of professional commitment scale for the nursing postgraduates were as follows: affective commitment 29.44 (SD 4.39), ideal commitment 22.64 (SD 4.54), normative commitment19.61(SD 2.71), continuance commitment 18.34 (SD 2.96). The ratings in each dimension of the career maturity scale were as follows: career decisiveness 26.34 (SD 3.68), career confidence 15.75 (SD 3.09), career value 18.05 (SD 3.51), career independence 13.45 (SD 2.19), relational dependence 13.18 (SD 3.01), career reference 18.33 (SD 2.57). Table 2 provides the detailed dimension score. 
Table 2

score of career maturity scale $(n=184, x \pm s)$

\begin{tabular}{|lllll|}
\hline Dimension & Minimum & Maximum & Total score & An average rating of items \\
\hline Career decisiveness & 16 & 37 & $26.34 \pm 3.68$ & $3.29 \pm 0.46)$ \\
\hline Career confidence & 6 & 27 & $15.75 \pm 3.10$ & $2.63 \pm 0.52$ \\
\hline career value & 6 & 28 & $18.05 \pm 3.51$ & $3.01 \pm 0.59$ \\
Career independence & 6 & 20 & $13.45 \pm 2.20$ & $3.36 \pm 0.55$ \\
\hline Relational dependence & 7 & 20 & $13.19 \pm 3.01$ & $3.30 \pm 0.75$ \\
\hline Career reference & 5 & 26 & $18.33 \pm 2.57$ & $3.06 \pm 0.43$ \\
\hline Career maturity & 52 & 133 & $105.12 \pm 11.13$ & $3.09 \pm 0.33$ \\
\hline
\end{tabular}

\subsection{Correlation between professional commitment and career maturity}

The dimensions and total scores of professional commitment and vocational maturity were analyzed by Pearson correlation analysis. The overall score of career maturity, career decisiveness and career independence were positively correlated with the total score of the professional commitment scale. whereas, the career confidence, career value, relational dependence, and career reference were negatively correlated with the Professional Commitment scale (Table 3).

Table 3

score of professional commitment scale

\begin{tabular}{|lllll|}
\hline Dimension & Minimum & Maximum & Total score & Average score of items \\
\hline Affective commitment & 16 & 40 & $29.44 \pm 4.39$ & $3.27 \pm 0.49)$ \\
\hline Ideal commitment & 7 & 34 & $22.64 \pm 4.54$ & $3.23 \pm 0.65$ \\
\hline Normative commitment & 6 & 25 & $19.61 \pm 2.71$ & $3.92 \pm 0.54$ \\
\hline Continuance commitment & 10 & 25 & $34 \pm 2.96$ & $3.06 \pm 0.49$ \\
\hline Specialty commitment & 45 & 124 & $90.0 \pm 12.09$ & $3.33 \pm 0.45$ \\
\hline
\end{tabular}

Table 4

Correlation analysis between professional commitment and career maturity

\begin{tabular}{|c|c|c|c|c|c|}
\hline & $\begin{array}{l}\text { Ideal } \\
\text { commitment }\end{array}$ & $\begin{array}{l}\text { Normative } \\
\text { commitment }\end{array}$ & $\begin{array}{l}\text { Continuance } \\
\text { commitment }\end{array}$ & $\begin{array}{l}\text { Affective } \\
\text { commitment }\end{array}$ & $\begin{array}{l}\text { Professional } \\
\text { commitment }\end{array}$ \\
\hline Career decisiveness & $0.33^{\star \star}$ & $0.26^{* *}$ & 0.11 & $0.26^{\star *}$ & $0.30^{\star \star}$ \\
\hline Career confidence & $0.15^{\star}$ & -0.01 & $-0.20^{\star \star}$ & 0.00 & 0.00 \\
\hline Career value & 0.04 & 0.02 & -0.23 & -0.04 & -0.05 \\
\hline Career independence & $0.337^{\star \star}$ & $0.306^{* *}$ & $0.272^{\star \star}$ & $0.325^{\star \star}$ & $0.380^{\star *}$ \\
\hline $\begin{array}{l}\text { Relational } \\
\text { dependence }\end{array}$ & -0.08 & 0.00 & $-0.24^{\star \star}$ & $-0.15^{\star}$ & -0.14 \\
\hline Career reference & $0.26^{*}$ & $0.27^{\star \star}$ & 0.10 & $0.35^{* *}$ & $0.31^{\star \star}$ \\
\hline Career maturity & $0.26^{\star *}$ & $0.21^{\star \star}$ & -0.08 & $0.18^{*}$ & $0.19^{\star *}$ \\
\hline
\end{tabular}

\section{Discussion}

Our survey results reflect two aspects. Firstly, the career maturity and professional commitment scores of postgraduate nursing students were medium level, which showed that the graduate students were unprepared to enter the workforce. Based on this observation, we suggested the introduction of new courses in colleges and universities to foster decision-making skills among the nursing post-graduates, these soft-skills allow the students to re-establish their employment objectives and career planning strategies. The current courses were focused on professional outlooks, such as nursing education, nursing management, clinical nursing, etc., and were not beneficial to develop career goals. Although the school provided help in terms of career guidance, yet they couldn't meet students' need as their primary interest were on the overall placement of post-graduates. Due to limited direction, the employment goals of the nursing graduates were not clear[11, 12]. Indeed, most career education programmes embody objectives that endorse the acquisition of information related to both the self and career options, the salience of students utilizing available career information has also been affirmed by attempts to promote career information-seeking behaviours through a variety of interventions [13].

From the score of the career maturity scale, our study reported the highest score of career independence, i.e. 3.36 (SD 0.55 ), which indicated that the nursing graduates were no longer affected by parents' decision, therefore the control over ones' career choice was relatively high. The lowest score of career 
confidence was 2.63 (SD 0.52), which might be related to the lack of clinical practice, confusion about career orientation, and the lack of professional confidence among the students from grade one to grade three in this study [14]. Japanese research showed that nursing students with higher career maturity were more likely to continue pursuing the profession. The higher individuals' career maturity, the greater the likelihood they will show achievement in career development and facility in making insightful decisions about occupational selection. Likewise, it is necessary to improve the active initiative of nursing postgraduates and enhance their vocational decision-making ability from multiple perspectives, so as to improve their vocational maturity and further alleviate the shortage of nursing talents with high academic degrees [15-16]. From the point of professional commitment scale score, norm commitment 3.92 (SD 0.54) was the highest, which was consistent with the reported result [17]. Due to the recent development in nursing schools, the higher score normative commitment than ever before. The nursing students were willing to take professional learning related responsibility to strengthen their medical, and vocational ethics, which improved their professional identity. Continuance commitment to a minimum score of ( $3.06 \pm 0.49)$ points, due to the higher nursing graduate student's career goals and career expectations, despite their significant knowledge and ideas are full of confidence, while in the clinical work their professional advantage and value can't give full play. Also they may affected by various influences, and hard to overcome these difficulties, in addition their clinical practice are limited, which lead them to produce career frustration and dissatisfaction and even thoughts of transition and resignation [18-19]. A study of South Korea confirmed that an awareness of the nursing profession does not guarantee full-time employment. Typically, the students did not invest time and energy on professional development, and they were not prepared to handle challenging job profiles in a clinical setting. More than $15 \%$ of the nursing staff at $56.6 \%$ of the hospitals were laid off work [14]. As evident, continued commitment has a profound impact on future career development, therefore, pre-employment vocational education is particularly important.

Secondly there is a positive correlation between the total score of professional commitment and the overall rating of career maturity $(r=0.19, P<0.01)$, which indicated that the ideal dedication, normative commitment and affective commitment in the professional commitment scale were all positively correlated with the overall score of career maturity, whereas, the continuance commitment is negatively correlated with career maturity, which proved that professional commitment and career maturity influence each other. The professional commitment of nursing graduate students reflected their recognition, love, willingness to pay, and the level of excellent performance. These attributes has a positive impact on career maturity. We can further enhance the professional maturity of nursing graduate students by working on their professional commitment score. Research showed that in the process of graduate education, nursing educators could encourage students to better understand their major by creating a positive learning atmosphere which boosts their professional commitment and autonomy during nursing work. These aspects enhanced vocational maturity[20]. By educating the professional attitude towards learning of the graduate students, and taking the initiative and positive professional learning attitude to learn, they can effectively improve their professional attitudes, further affirm the majors they have studied, and improve their professional commitment. Besides professional commitment, vocational education for postgraduates also improved their self-confidence, cognitive ability, improved work efficiency, and thus enhanced their career maturity. Therefore, professional education in medical colleges was reported to be essential $[10,21]$. In summary, we can take targeted educational measures to improve the vocational maturity of nursing postgraduates by understanding their commitment to nursing. To further cultivate nursing talents and reduce the turnover rate, it is suggested to carry out individualized vocational education.

\section{Limitations}

Several limitations shoud be considered. First, this study was conducted in Sichuan province. Although nursing graduates from other areas also participated in this study, their proportion was relatively small, and, hence, their representation did not wholly reflect the situation in China. Second, this was a crosssectional study without longitudinal observation of the subjects, however, as opposed to longitudinal research, it is unable to provide an analysis of how these variables change over time. Due to time constraints, we only conducted a questionnaire survey and did not carry out any intervention. Additionally, the use of Likert questions forced respondents to choose an answer rather than providing an open response. However, as a part of our future research, we prepared a longitudinal study after conducting a questionnaire survey of the postgraduate nursing students, these scientific data could advance future career aspiration of the nursing post-graduate students.

\section{Conclusions}

The results of this study showed that the career maturity and professional commitment of Chinese nursing postgraduate students were average, and the total score of career maturity is positively correlated with the overall score of professional commitment. We suggested to provide nursing graduate students with relevant professional development courses as early as possible. The scientific and practical help allows them to adapt to clinical work, and continue to make contributions to a nursing career.

\section{Abbreviations}

SD

standard deviation;SPSS $₫$ Statistical Packages for Social Science

\section{Declarations}

\section{Acknowledgements}

Much appreciation goes to the head nurse Zhuoyuanyuan Chen, the Affiliated hospital of Southwest Medical University who provided general support for this study, and much appreciation goes to the nursing students who participated in this study.

\section{Authors' contributions}


KS: conceptualization, design of the work, Analysis, Supervision.

$\mathrm{CL}$ : the acquisition and interpretation of data, drafting and substantively revising the work.

JP: the acquisition and interpretation of data.

MJ: drafting and substantively revising the work.All authors are able to take responsibilities for relevant portions of the paper.

\section{Funding}

This study was supported by Health Commission of Sichuan Province [Project number 19PJ044].

\section{Availability of data and materials}

The datasets generated during and/or analyzed during the current study are available from the corresponding author on reasonable request.

\section{Ethics approval and consent to participate}

This study approved by research ethics committee of the Affiliated hospital of Southwest Medical University (Approval Number:: KY2019155). The study was carried out in accordance with the declaration of Helsinki, including, but not limited to, there being no potential harm to participants, that the anonymity of participants was guaranteed, and that written informed consent of participants was obtained.

\section{Consent for publication}

"Not applicaable".

\section{Competing interests}

The authors declare that they have no competing interests.

\section{Author details}

${ }^{1}$ People's Hospital of Deyang City, Deyang, Sichuan, China. ${ }^{2}$ School of Nursing, Southwest Medical University, Dean of nursing school, Luzhou, China.

\section{References}

1. Wilkinson J, Carryer J, \& C.B., 2018. Impact of postgraduate education on Source Int Nurs Rev SO 2018 Mar 22[PMIDT29569420].pdf. https://doi.org/10.1111/inr.12437.

2. Wang Y, Zhang L, Tian S, Wu J, Lu J, Wang F, Wang Z. The relationship between work environment and career success among nurses with a master's or doctoral degree: A national cross-sectional study. Int J Nurs Pract e12743. 2019. https://doi.org/10.1111/ijn.12743.

3. TianShuangyue,WangYi WuJie, WangZhiwen Z. The relationship between practice environment and professional values among nurses with master or doctoral degree in tertiary hospitals. Chinese Nurs Manag. 2018;18:33-7. https://doi.org/10.3969/j.issn.1672-1756.2018.01.010.

4. Wang Yi W, Zhiwen Wu, Jie, ZhangLixin LuJie, Yan Z, X.B. The working status of nurses with master or doctoral degree in tertiary hospitals in China. Chinese Nurs Manag. 2018;18:43-7. https://doi.org/10.3969/j.issn.1672-1756.2018.01.012.

5. Sundler AJ, Blomberg K, Bisholt B, Eklund A, Windahl J, Larsson M. Experiences of supervision during clinical education among specialised nursing students in Sweden: A cross-sectional study. Nurse Educ Today. 2019;79:20-4. https://doi.org/10.1016/j.nedt.2019.05.009.

6. Peng H. Career maturity and state anxiety of Taiwanese college student athletes given cognitive career-oriented group counseling. Psychological reports. 2006;99(3):805-12. https://doi.org/10.2466/PR0.99.3.805-812.

7. ZhuangQianling, ShenSimei C. The relationship between practice environment and professional values among nurses with master or doctoral degree in tertiary hospitals. Chinese Nurs Res. 2014;28:3316-8. https://doi.org/10.3969/j.issn.1009-6493.2014.026.054.

8. Cheng C, Yang L, Chen Y, Zou H, Su Y, Fan X. Attributions, future time perspective and career maturity in nursing undergraduates: Correlational study design. BMC Med Educ. 2016;16:1-8. https://doi.org/10.1186/s12909-016-0552-1.

9. Shi Haixia C. Features of vocation maturity of college nursing students and nursing undergraduates. J od Nurs. 2015;22:33-6. https://doi.org/10.16460/j.issn1008-9969.2015.20.033.

10. Hur Y, Cho AR, Song EJ, Kim S. Evaluation of a systematic career coaching program for medical students in Korea using the Career Readiness Inventory. J Educ Eval Health Prof. 2018;15:10. https://doi.org/10.3352/jeehp.2018.15.10.

11. Kong L, Chen X, Shen S, et al. Professional commitment and attributional style of medical-college nursing students in China: A cross-sectional study. Nurse Educ Today. 2016;40:154-60. doi:10.1016/j.nedt.2016.02.027.

12. Mingyue Hu, ZhangYue C. The employment of students graduated from an academic or a clinical master's program in nursing. J Nurs Sci. 2017;32:43-7. https://doi.org/10.3870/j.issn.1001-4152.2017.04.064.

13. Shevlin M. Career education: an application of latent growth curve modelling to career information-seeking behaviour of school pupils. Br J Educ Psychol. 2006;76(Pt 1):141-53. http://nc.yuntsg.com/one1.do. 
14. Lim JY, Kim MA, Kim SY, Kim EJ, Lee JE, Ko YK. The effects of a cognitive-behavioral therapy on career attitude maturity, decision making style, and selfesteem of nursing students in Korea. Nurse Educ Today. 2010;30:731-6. https://doi.org/10.1016/j.nedt.2010.01.014.

15. Mukaihata T. Correlation between job security as motivation and career maturity among Japanese nursing students. J Rural Med. 2018;13:168-71. https://doi.org/10.2185/jrm.2961.

16. Park IJ. The role of affect spin in the relationships between proactive personality, career indecision, and career maturity. Front Psychol. 2015;6:1-10. https://doi.org/10.3389/fpsyg.2015.01754.

17. ChenYuhua. 2012. The Status of nursing undergraduates'career maturity and its influencing factors. University of South China. http://kns.cnki.net/KCMS/detail/detail.aspx? dbcode=CMFD\&dbname=CMFD201301\&filename=1012458656.nh\&v=MTAyNTRubFc3ck1WRjI2SExIOUZ0ZkpxWkViUEISOGVYMUx1eFITNORoMVQzcVR

18. Bruce JC, Baumann J, Schmollgruber S. 2019. Does improved postgraduate capacity shift the balance of power for nurse specialists in a low-income country: a mixed methods study. J Adv Nurs 0-2. https://doi.org/https://doi.org/10.1111/jan.14109.

19. Dan LIU, Nursing B. 2018. Mediating Effect of Professional Commitment between Career Maturity and Core Self-evaluation of Nursing Students in Higher Vocational Colleges. https://doi.org/10.16460/j.issn1008-9969.2018.17.031.

20. Kinsella D, Fry M, Zecchin A. Motivational factors influencing nurses to undertake postgraduate hospital-based education. Nurse Educ Pract. 2018;31:5460. https://doi.org/10.1016/j.nepr.2018.04.011.

21. Baxter R, Edvardsson D. Impact of a critical care postgraduate certificate course on nurses' self-reported competence and confidence: A quasiexperimental study. Nurse Educ Today. 2018;65:156-61. https://doi.org/10.1016/j.nedt.2018.03.004. 